\title{
FTIR AND WAXS STUDIES ON SIX VEGETAL FIBERS
}

\author{
RANJITHA KEMPAIAH, ${ }^{*}$ GAYATHRI GURAPPA, ${ }^{*}$ RITU TOMAR, ${ }^{*}$ \\ MATHEUS POLETTO, ${ }^{* *}$ HEITOR LUIZ ORNAGHI JUNIOR, ${ }^{* *}$ VENKATASAMY ANNADURAI* and \\ RUDRAPPA SOMASHEKAR ${ }^{* * *}$
}

*Department of Physics and Research Centre, Sambhram Institute of Technology, Bangalore 560 097, India

${ }^{* *}$ LPOL, University of Caxias do Sul (UCS), Francisco Getúlio Vargas 1130, Caxias do Sul, Rio Grande do Sul 95070-560, Brazil

${ }^{* * *}$ Regional Institute of Engineering and Department of Studies in Physics, University of Mysore, Manasagangotri, Mysore 570 006, India

Corresponding author: R. Kempaiah, ranjithak.physics@gmail.com

Received April 11, 2019

\begin{abstract}
The microstructural parameters of various vegetal fibers and their respective native cellulose have been studied using wide angle X-ray scattering (WAXS) and FT-IR spectroscopy. The crystal imperfection parameters, such as crystal size $<\mathrm{N}>$, lattice strain (g) and enthalpy $\left(\alpha^{*}\right)$, have been determined by profile analysis using Warren's method. The results were cross-checked with those obtained by matching the stimulated intensity profile obtained from one-dimensional Hosemann's paracrystalline model. In all this computation, we have used (110) and (200) reflection observed in these varieties of vegetal fibers and their native cellulose. We have also computed volume weighted and surface weighted crystal size, and compared the values of these parameters. Details of the microstructural parameters were obtained using an analytical function considering asymmetric functions, and the variations found in crystallite shape and size were attributed to differences in the chemical composition of lignin and cellulose among the fibers.
\end{abstract}

Keywords: vegetal fibers, cellulose, WAXS, crystal imperfection parameter, volume weighted crystal size, surface weighted crystal size, FTIR

\section{INTRODUCTION}

The last few decades have revealed a growing interest in the research and development of polymeric and composite materials from renewable sources. ${ }^{1-7}$ As the most abundant component in most plants, cellulose is an almost inexhaustible polymeric raw material from renewable sources. Natural cellulose-based materials, such as vegetal fibers, have been used as engineering materials for thousands of years and are still used currently, as demonstrated by the huge number of forest product-based industries worldwide. However, what makes cellulose such an important material for the development of polymeric and composite materials? The cellulose macromolecule is made up of repeating glucose units that generate surprising specificity and impressively diverse architectures, reactivates and functions. ${ }^{8}$ The reactions and properties of native cellulose are determined by the isolation process used, the number of inter and intra-molecular hydrogen bonds, the chain lengths, chain length distribution, crystallinity and the distribution of functional groups within the repeating units and along the polymer chains. ${ }^{8-11}$ These important parameters make cellulose a unique material.

Cellulose is a natural polymer consisting of ringed glucose molecules. The repeat unit comprises two anhydroglucose rings $\left(\mathrm{C}_{6} \mathrm{H}_{10} \mathrm{O}_{5}\right)_{n}$ linked together through an oxygen covalently bonded to the $C_{1}$ of one glucose ring and the $C_{4}$ of the adjoining ring ( $1 \rightarrow 4$ linkage), the so-called $\beta$ 1,4 glucosidic bond. ${ }^{8,12-14}$ The degree of polymerization, $n$, varies between 10,000 and 15,000 , where $n$ is dependent on the cellulose source material. ${ }^{12,15}$ Each repeating unit contains three hydroxyl groups, these hydroxyl groups with their ability to make hydrogen bonds between cellulose chains, govern the physical properties of cellulose. ${ }^{15}$ 
The intra-chain hydrogen bonding between the hydroxyl groups and the oxygen of the adjoining ring molecules stabilizes the linkage and results in the linear configuration of the cellulose chain. ${ }^{12}$ During cellulose formation, van der Waals and intermolecular hydrogen bonds between the hydroxyl groups and the oxygen of adjacent molecules promotes aggregation of multiple cellulose chains forming fibrils., ${ }^{8,12}$ The intra- and inter-chain hydrogen bonding network makes cellulose a relatively stable polymer, and gives the cellulose fibrils high axial stiffness. ${ }^{12}$ The high cohesive energy ensuing from these physicochemical interactions explains why cellulose does not possess a liquid state ${ }^{16}$ and these cellulose fibrils are the main reinforcement phase in trees and plants. Within these cellulose fibrils, there are regions where the cellulose chains are arranged in a highly ordered crystalline structure and regions with a low level of order or amorphous regions. ${ }^{12,15}$

The polymorphy of cellulose and its derivatives has been well documented. These are cellulose I, II, III and IV. ${ }^{8,11,17}$ Cellulose I, or native cellulose, is the form found in nature. Its structure is thermodynamically metastable and can be converted to either cellulose II or III. ${ }^{12,15}$ This work focuses on the characterization of the cellulose I structure, which is the crystal structure naturally produced by a variety of organisms. Cellulose I has two polymorphs, a monoclinic structure $I_{\beta}$ and a triclinic structure $I_{\alpha}$, which coexist in various proportions depending on the cellulose structure. ${ }^{12,18}$ The $\mathrm{I}_{\alpha}$ is a rare form, whereas $I_{\beta}$ is the dominant polymorph for higher plants. ${ }^{14,19}$ The $I_{\alpha}$ polymorph is metastable and can be converted into $I_{\beta}$ by hydrothermal treatments in alkaline solution. ${ }^{12,19}$

In the $I_{\alpha}$ and $I_{\beta}$ polymorph structures, the $I_{\alpha}$ unit cell contains one cellulose chain, the unit cell parameters being $\mathrm{a}=0.672 \mathrm{~nm}, \mathrm{~b}=0.596 \mathrm{~nm}, \mathrm{c}=$ $1.040 \mathrm{~nm}, \alpha=118.08^{\circ}, \beta=114.80^{\circ}, \gamma=$ $80.375^{\circ} .{ }^{15}$ The $\mathrm{I}_{\beta}$ unit cell contains two cellulose chains, and the unit cell parameters are a $=0.778$ $\mathrm{nm}, \mathrm{b}=0.820 \mathrm{~nm}, \mathrm{c}=1.038 \mathrm{~nm}$ and $\gamma=96.5^{\circ} . .^{19,20}$ Three lattice planes with approximate d-spacings of $0.39 \mathrm{~nm}, 0.53 \mathrm{~nm}$ and $0.61 \mathrm{~nm}$ correspond to the $I_{\alpha}$ lattice planes (110), (010) and (100) for the triclinic structure, and to the $\mathrm{I}_{\beta}$ lattice planes (200), (100), and (1-10) for the monoclinic structure. ${ }^{12,19}$ The main difference between the $\mathrm{I}_{\alpha}$ and $I_{\beta}$ polymorph structures is the relative displacement of cellulose sheets along the (110) lattice plane in the triclinic structure and the (200) lattice plane in the monoclinic structure, called "hydrogen-bonded" planes, in the chain axis direction. ${ }^{8,12}$ In $\mathrm{I}_{\alpha}$, there is a relative displacement of c/4 between each subsequent hydrogen-bonded plane, while for $I_{\beta}$, the displacement alternates between $\pm \mathrm{c} / 4$ through van der Waals interactions. ${ }^{12,19-22}$

Therefore, knowledge of the properties of native cellulose before using it in composites can contribute to the development of composites with better mechanical properties. ${ }^{23}$ In order to better understand the relationships between native cellulose structure and properties, the aim of this work was to establish the structural differences among some varieties of vegetal fibers, namely kenaf, jute, sisal, curaua, ramie and buriti, commonly used as reinforcing fillers in composite materials. To achieve this objective, FTIR spectroscopy and X-ray diffraction (XRD) analysis were used.

\section{Theory}

The intensity of a profile in the direction joining the origin to the center of the reflection can be expanded in terms of Fourier Cosine series: ${ }^{24-26}$

$$
\mathrm{I}(\mathrm{s})=\sum_{\mathrm{n}=-\infty}^{\infty} \mathrm{A}(\mathrm{n}) \cos \left\{2 \pi \mathrm{nd}\left(\mathrm{s}-\mathrm{s}_{\mathrm{o}}\right)\right\}
$$

where the coefficients of the harmonics $A(n)$ are functions of the crystallite size and the disorder of the lattice. Here, $s$ is $(\sin \theta) / \lambda$ and $d$ is the lattice spacing. The Fourier coefficients ${ }^{27-32}$ can be expressed as:

$$
\mathrm{A}(\mathrm{n})=\mathrm{A}_{\mathrm{s}}(\mathrm{n}) \cdot \mathrm{A}_{\mathrm{d}}(\mathrm{n})
$$

For a paracrystalline material, such as vegetal fiber, $A_{d}(n)$ turns out to be: ${ }^{26,33}$

$$
A_{d}(n)=\exp \left(-2 \pi^{2} m^{2} \mathrm{ng}^{2}\right)
$$

where $m$ is the order of reflection and $g(=\Delta d / d)$ is the lattice strain. For a probability distribution of column lengths $P(i)$, we have:

$$
\mathrm{A}_{\mathrm{s}}(\mathrm{n})=1-\frac{\mathrm{nd}}{\mathrm{D}}-\frac{\mathrm{d}}{\mathrm{D}}\left[\int_{0}^{\mathrm{n}} \mathrm{iP}(\mathrm{i}) \mathrm{di}-\mathrm{n} \int_{0}^{\mathrm{n}} \mathrm{P}(\mathrm{i}) \mathrm{di}\right]
$$

where $\mathrm{D}=\langle\mathrm{N}\rangle \mathrm{d}_{\mathrm{hkl}}$ is the crystallite size. In the presence of two orders of reflections from the set of Bragg planes, Warren and Averbach (1952) developed a method of obtaining the crystal size $(<\mathrm{N}>)$ and lattice strain (g). However, in wood fibers, multiple reflections are very rarely found. So, to find the finer details of the microstructure, we approximate the size profiles by a simple analytical function for $\mathrm{P}(\mathrm{i})$. Here, we have 
considered only asymmetric functions. In this way, we can still complete the microstructure parameters by a single order method.

\section{Exponential distribution}

It is assumed that there are no columns containing fewer than $p$ units and those with more decay exponentially. Thus we have: ${ }^{34}$

$$
\mathrm{P}(\mathrm{i})= \begin{cases}0 & \text { ifp }<i \\ \alpha \exp \{-\alpha(\mathrm{i}-\mathrm{p})\} & \text { ifp } \geq \mathrm{i}\end{cases}
$$

where $\alpha=(1 /(\mathrm{N}-\mathrm{p})$. Substituting Equation (5) in Equation (4), we obtain equation (6):

$$
A_{s}(n)= \begin{cases}A(0)\left(1-\frac{n}{\langle N\rangle}\right) & \text { ifn } \leq p \\ A(0) \exp \{-\alpha(n-p)\} /(\alpha N) & \text { ifn } \geq p\end{cases}
$$

\section{Surface and volume weighted crystal sizes}

The surface weighted and volume weighted values are computed using a well-established procedure using the parameters $\langle N>$ and $\alpha$ or $\beta$. The relations are given by: ${ }^{33}$

$$
D_{\mathrm{v}, \mathrm{s}}=\frac{\int_{0}^{\infty} \mathrm{LP}_{\mathrm{v}, \mathrm{s}}(\mathrm{L}) \mathrm{dL}}{\int_{0}^{\infty} \mathrm{P}_{\mathrm{v}, \mathrm{s}}(\mathrm{L}) \mathrm{dL}}
$$

where $\mathrm{P}_{\mathrm{v}, \mathrm{S}}(\mathrm{L})$ is the appropriate crystal size distribution functions and $L=n d_{h k l}$. Here, $n$ is the harmonic number. ${ }^{35}$

\section{EXPERIMENTAL}

\section{Materials}

The varieties of vegetal fiber samples used in this study were as follows: Hibiscus cannabinus (kenaf), Corchorus capsularis (jute), Agave sisalana (sisal), Ananus erectifolius (curaua), Boehmeria nivea (ramie) and Mauritia flexuosa (buriti). Kenaf, jute and sisal fibers were supplied by Tapetes São Carlos Technology from São Carlos, Brazil, as sheets. Curaua fiber was obtained from CEAPAC, a support center for community action projects in Santarem, Brazil. Ramie roving was purchased from Sisalsul Fibras Naturais from São Paulo, Brazil, and buriti fiber was obtained from Sisalsul Fibras Naturais from Caxias do Sul, Brazil. All of the fiber samples were dried at $105^{\circ} \mathrm{C}$ for $24 \mathrm{~h}$ in a vacuum oven before the tests. The samples were ground in a knife mill and the average fiber particle length used in all analyses was around $200 \mu \mathrm{m} .{ }^{36}$ More information about fiber characterization can be found in earlier publications. ${ }^{6,37}$

\section{FT-IR spectroscopy}

Fourier transform infrared spectroscopy analysis was carried out on FTIR Nicolet IS10 Thermo Scientific equipment, using 32 scans, in the range of $4000-400 \mathrm{~cm}^{-1}$ at a resolution of $4 \mathrm{~cm}^{-1}$. KBr pellets (5 mg of sample for $100 \mathrm{mg}$ of $\mathrm{KBr}$ ) were prepared. Three measurements were made for each sample and the average value was considered.

\section{$X$-ray diffraction patterns}

The powdered samples were compression moulded under a pressure of 5 tons for 2 min to obtain pellets before XRD analysis. X-ray diffractograms were collected using a sample holder mounted on an XRD 6000 Diffractometer (Shimadzu, Kyoto, Japan), with monochromatic $\mathrm{CuK} \alpha$ radiations $(\lambda=0.15419 \mathrm{~nm})$. The generator was utilized at $40 \mathrm{kV}$ and $30 \mathrm{~mA}$, and the intensities were measured in the range of $5^{\circ}<2 \theta<40^{\circ}$, typically with scan steps of $0.05^{\circ}$ at $1.5^{\circ} / \mathrm{min}$ ( $\left.2 \mathrm{~s} / \mathrm{step}\right)$. Peak separations were carried out using Gaussian deconvolution. X-ray diffraction patterns of various vegetal fibers and their native cellulose are given in Figure 1 (a-f).

\section{Determination of Fourier coefficients and} instrumental broadening corrections

The profile of a Bragg reflection was assumed to be symmetric and the half that had the greatest range before the intrusion of other reflections was used. The background level was taken as that at which intensity either begins to increase with a distance from the peak or becomes uniform. This was subtracted from all the points and the intensity was assumed to be zero over the rest of the range required by the theory. The scattering angle was transformed to $s=\sin \theta / \lambda$ and the values of intensity were interpolated at equal intervals of $s$ of $0.001 \AA^{-1}$, after which they were corrected for Lorentz and polarization factors.

Fourier coefficients were determined using a program written in FTN77 language, and these were again used to predict the intensity data, so that the difference between the predicted and the experimental data is less than $1 \%$ of the mean value. Normally, the number of coefficients is of 20-30, which satisfied the condition. ${ }^{38}$ Instrumental broadening corrections were applied. For this purpose, standard X-ray profiles at appropriate $2 \theta$ angles of the samples were obtained from standard samples, such as ball milled iron powder, and were used for subtracting the instrumental broadening by the Stokes deconvolution method. These corrections are relatively small in polymeric samples when compared to metal oxide compounds. $^{33,39}$ We have extensively checked the reliability of this single order method of obtaining the strain parameters in our earlier papers, using manmade polymer samples and employing both multiple and single order methods. ${ }^{33,34,40}$

\section{RESULTS AND DISCUSSION}

The FT-IR spectra for the vegetal fibers studied are shown in Figure 2. It can be observed that there is a strong broad band around $3400 \mathrm{~cm}^{-}$ 
${ }^{1}$, which is assigned to different $\mathrm{O}-\mathrm{H}$ stretching modes, ${ }^{41}$ and two bands around $2920 \mathrm{~cm}^{-1}$ and $2850 \mathrm{~cm}^{-1}$, related to asymmetric and symmetric methyl and methylene stretching groups, which are notably present in the spectra for cellulose. ${ }^{5,42}$ However, these two bands are more prominent at $2918 \mathrm{~cm}^{-1}$ and $2849 \mathrm{~cm}^{-1}$, respectively, for buriti fiber. This might be attributed to the higher extractive contents in this fiber, comprising organic extractives, such as fatty acid, methyl, esters and phenolic acid. Methyl esters contain methyl and methylene groups. ${ }^{42-45}$ In the

(a)

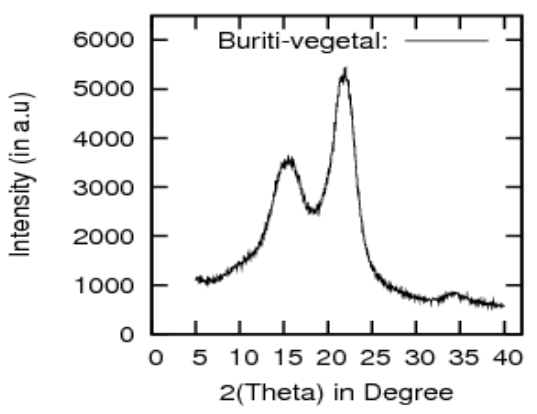

(c)

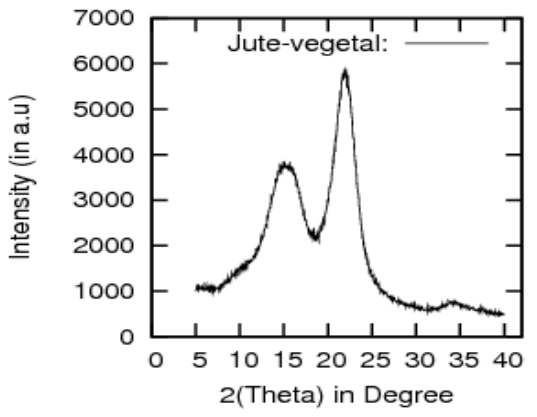

(e)

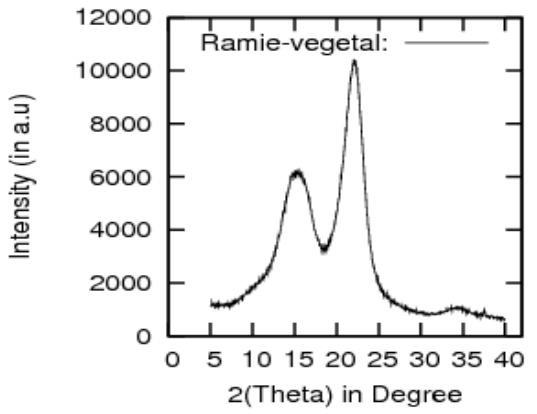

fingerprint region, the bands at $1595 \mathrm{~cm}^{-1}, 1510$ $\mathrm{cm}^{-1}$ and $1270 \mathrm{~cm}^{-1}$ are assigned to $\mathrm{C}=\mathrm{C}, \mathrm{C}-\mathrm{O}$ stretching and bending vibrations different groups present in lignin. ${ }^{5,42-45}$ The bands at $1460 \mathrm{~cm}^{-1}$, $1425 \mathrm{~cm}^{-1}, 1335 \mathrm{~cm}^{-1}, 1220 \mathrm{~cm}^{-1}$ and $1110 \mathrm{~cm}^{-1}$ are characteristic of C-H, C-O deformation, bending or stretching vibrations of many groups in lignin and carbohydrates. ${ }^{36,42-45}$ The bands at $1735 \mathrm{~cm}^{-1}, 1375 \mathrm{~cm}^{-1}, 1240 \mathrm{~cm}^{-1}, 1165 \mathrm{~cm}^{-1}, 1060$ $\mathrm{cm}^{-1}$ and $1030 \mathrm{~cm}^{-1}$ are assigned to $\mathrm{C}=\mathrm{O}, \mathrm{C}-\mathrm{H}, \mathrm{C}-$ $\mathrm{O}-\mathrm{C}$ and $\mathrm{C}-\mathrm{O}$ deformation or stretching vibrations of different groups in carbohydrates. ${ }^{5,42,43}$

(b)

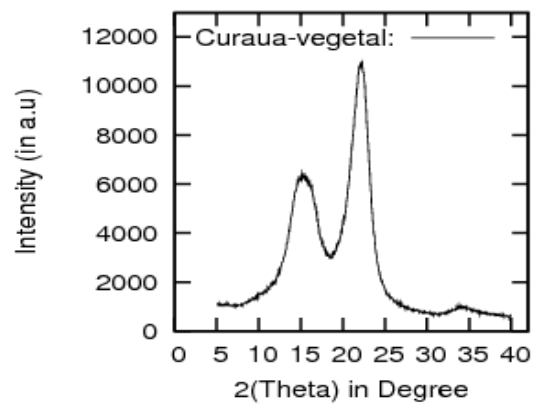

(d)

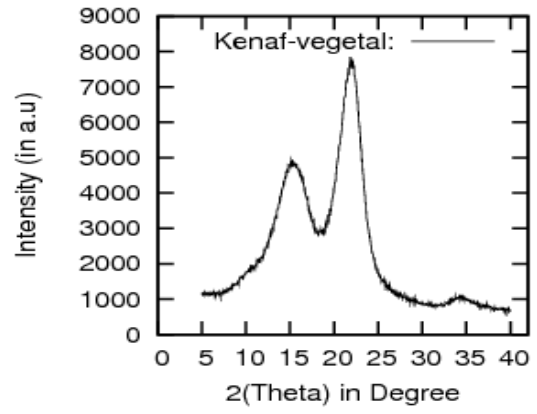

(f)

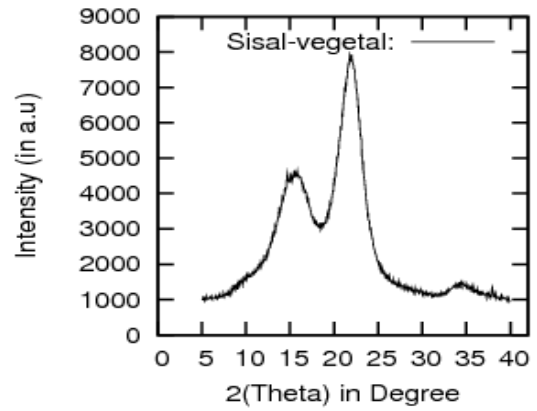

Figure 1: X-ray diffractograms for a) buriti, b) curaua, c) jute, d) kenaf, e) ramie and f) sisal vegetal fibers

The hydrogen bonds are considered to be responsible for various properties of native cellulose lignin and natural fibers. Thus, the closer the cellulose chains, the greater the interaction between the adjacent chains, resulting in more and stronger hydrogen bonds, which can lead to greater packing of cellulose chains, resulting normally in fibers with higher 
mechanical and thermal properties. ${ }^{5,46}$ In addition, an intra-molecular hydrogen bond vibration for cellulose appears at around $3432 \mathrm{~cm}^{-1} .47,48$

According to other studies, ${ }^{46-49}$ the intramolecular hydrogen bond in a phenolic group in lignin is observed at around 3568-3577 $\mathrm{cm}^{-1}$. 36,49 In cellulose, the intra-molecular hydrogen bond vibration appears at around $3432 \mathrm{~cm}^{-1}, 36,47,48$ another intra-molecular hydrogen bond in cellulose normally occurs at $3342 \mathrm{~cm}^{-1}$. ${ }^{48}$ The two characteristic bands assigned to the two crystalline cellulose allomorphs, cellulose $\mathrm{I}_{\alpha}$ and cellulose $\mathrm{I}_{\beta}$, also occur in the region of $3220-3280$ $\mathrm{cm}^{-1} \cdot{ }^{42,46}$ A very small peak, normally shifting to lower wavenumbers at $3221 \mathrm{~cm}^{-1}$, is attributed to hydrogen bonds only in cellulose $\mathrm{I}_{\alpha} \cdot{ }^{36,42,46,47}$ The band at $3221 \mathrm{~cm}^{-1}$ is assigned to the intramolecular hydrogen bonds present only in triclinic $\mathrm{I}_{\alpha}$ cellulose, whereas the band close to $3277 \mathrm{~cm}^{-1}$ is proportional to the amount of monoclinic cellulose $\mathrm{I}_{\beta}$.

The energy of hydrogen bonds $E_{H}$ for several $\mathrm{OH}$ stretching bonds has been calculated using the equation $E_{H}=\frac{1}{k}\left(\frac{\gamma_{0}-\gamma}{\gamma_{0}}\right)$, where $\gamma_{0}$ is the standard frequency corresponding to free $\mathrm{OH}$ groups (3560 $\left.\mathrm{cm}^{-1}\right), \gamma$ is the frequency of bonded $\mathrm{OH}$ groups and $k$ is a constant $\left(1 / \mathrm{k}=2.625 \times 10^{2} \mathrm{~kJ}\right) .^{50}$

The hydrogen bond distances $\mathrm{R}$ are obtained using the equation $\gamma=4430 \times(2.84-\mathrm{R}) \mathrm{cm}^{-1}$, where $\Delta \gamma=\gamma_{0}-\gamma, \gamma_{0}$ is the monomeric $\mathrm{OH}$ stretching frequency, which is taken to be 3600 $\mathrm{cm}^{-1}$, and $\gamma$ is the stretching frequency observed in the infrared spectrum of the sample. ${ }^{51}$

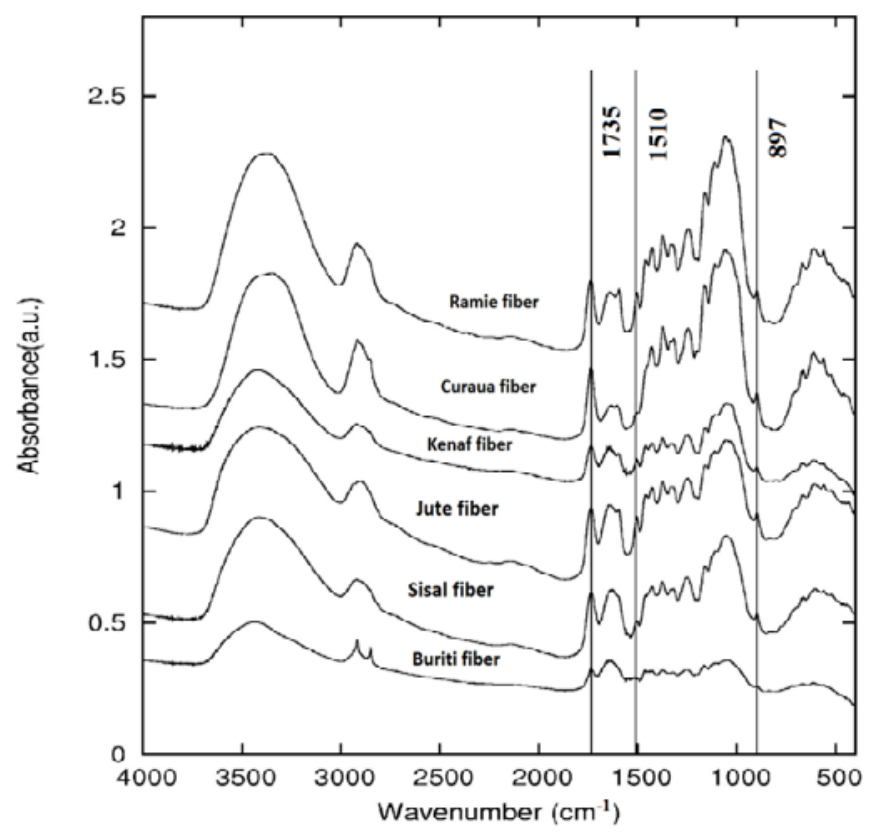

Figure 2: FTIR spectra of buriti, sisal, jute, kenaf , curaua and ramie and vegetal fibers

Table 1

Chemical composition of the vegetal fibers used in this study

\begin{tabular}{lcccccc}
\hline Fibers & $\begin{array}{c}\text { Cellulose } \\
(\mathrm{wt} \%)\end{array}$ & $\begin{array}{c}\text { Hemicelluloses } \\
(\mathrm{wt} \%)\end{array}$ & $\begin{array}{c}\text { Lignin } \\
(\mathrm{wt} \%)\end{array}$ & $\begin{array}{c}\text { Pectin } \\
(\mathrm{wt} \%)\end{array}$ & $\begin{array}{c}\text { Waxes } \\
\text { (wt\%) }\end{array}$ & $\begin{array}{c}\text { Extractives } \\
(\mathrm{wt} \%)\end{array}$ \\
\hline Curaua & $71-74$ & $9.9-21$ & $7.5-11$ & - & $0.79-0.9$ & $2.5-2.8$ \\
Jute & $45-71$ & $13.6-21$ & $12-26$ & $0.2-10$ & 0.5 & 2 \\
Kenaf & $31-72$ & $20.3-23$ & $9-19$ & $3-5$ & - & $2-5$ \\
Ramie & $68.6-91$ & $5-16.7$ & $0.6-0.7$ & $1.9-2$ & 0.3 & 6 \\
Sisal & $65-67$ & 12 & 9.9 & $2-10$ & $0.3-2$ & $0.8-2$ \\
Buriti & $47-63$ & $4-26.6$ & $21-27$ & - & - & $5.4-6.0$ \\
\hline
\end{tabular}


According to the data in Table $1,{ }^{36,62-66}$ ramie, sisal and buriti fibers had higher quantities of lignin, which may contribute to the formation of several intramolecular hydrogen bonds between neighboring phenolic groups in lignin. Such bonding reduces the distance between the neighboring phenolic groups, as can be seen by the lower hydrogen bond distance values for these fibers, compared to those for other fibers.

The hydrogen bond energy values for the bands at $3423 \mathrm{~cm}^{-1}$ and $3342 \mathrm{~cm}^{-1}$ are similar for all the fibers studied. However, considering these two bands in buriti fiber, it may be noted that they reach higher values, which may indicate a higher number of intra-molecular hydrogen bonds in cellulose in this fiber. These higher values were attributed to lower hydrogen bond distances, which may contribute to higher interactions between intra-molecular cellulose chains. The energy values at $3278 \mathrm{~cm}^{-1}$ and $3221 \mathrm{~cm}^{-1}$ are related to the cellulose allomorph forms for all the fibers studied. ${ }^{53,56}$

The energy of the hydrogen bonds and hydrogen bond distances for the varieties of fibers studied $^{5}$ are given in Table 2. Curaua, jute and kenaf fibers present a lower energy of hydrogen bonds at $3567 \mathrm{~cm}^{-1}$. This could be associated with a higher quantity of absorbed water in the structure of these fibers, since the band at 3567 $\mathrm{cm}^{-1}$ is also assigned to the weakly absorbed water. ${ }^{48,52}$

The experimental X-ray diffraction profile between $\mathrm{s}_{\mathrm{o}}+\mathrm{s}_{\mathrm{o}} / 2$ was matched with the simulated profile using Equations (1), (2), (3), (6) and (8), for various values of $\langle\mathrm{N}\rangle, \mathrm{g}, \alpha$ and a parameter for background correction, so as to minimize the difference between them. For this purpose, a minimization algorithm SIMPLEX, which is a multidimensional program, was used. $^{54}$ Initial $<\mathrm{N}>$ the crystal size, g and the width of crystal distribution function values were determined using a well-established procedure. ${ }^{33}$ The obtained microstructural parameters for the investigated vegetal fibers, using different Bragg reflections, are given in Table 3.

Figures 3 (a-f) and 4 (a-f) show the goodness of the fit between the simulated and the experimental intensity profiles for (110) and (200) prominent reflections, which is less than $10 \%$ of the mean value. Here, we compute:

$\Delta^{2}=\left[\mathrm{I}_{\mathrm{cal}}-\left(\mathrm{I}_{\exp }+\mathrm{BG}\right)\right]^{2} /$ number of points
We also observe from these calculations that the exponential distribution function gives a better fit in these vegetal fibers and their native cellulose. It is evident from Table 3 that the strains present in these natural vegetal fibers and their native cellulose are very small and varies between $0.1 \%$ and $1.5 \%$, when compared to polymer fibers. ${ }^{55}$

Figure $5(\mathrm{a}, \mathrm{b})$ shows the variations in the crystal size distribution along (110) and (200) for the vegetal fibers and their native cellulose. ${ }^{57}$ The significant variation of $<\mathrm{N}>$ crystal size and lattice strain $g$ is illustrated in Table 3. We have computed surface and volume weighted crystal sizes and we find that they are different in different directions, indicating that the shape of the crystallite is not spherical, but ellipsoid. There is also a significant variation of these microcrystalline parameters among the different types of vegetal fibers and their native cellulose. The reason for such a variation, even though these are made up of same chemical units, lies in the fact that the numbers of weak inter- and intramolecular hydrogen bonds, such as $\mathrm{C}=\mathrm{O}$, C$\mathrm{H}, \mathrm{C}-\mathrm{O}-\mathrm{C}$ and $\mathrm{C}-\mathrm{O}$, which determine the extent of ordering in the vegetal fibers and their native cellulose, vary significantly. In fact, there is a direct relation between the size and the shape of the crystallites with the number of hydrogen bonds in these fibers. For a better perspective of the results obtained for these fibers, we have projected the crystallite shape into a plane using the equation:

$$
\left(\frac{2}{D_{\mathrm{hkl}}}\right)^{2}=\left(\frac{\cos \phi}{\mathrm{Y}}\right)^{2}+\left(\frac{\sin \phi}{\mathrm{X}}\right)^{2}
$$

where $\Phi$ is the angle between (hkl) planes. This $\Phi$ can be determined using the cell parameters reported here. The obtained crystallite shape is given in Figure 6.

It is evident from this figure that the volume of the ellipsoid shape in the varieties of vegetal fibers under study is comparatively higher than that of their native cellulose. As mentioned earlier, the weak intra- and intermolecular hydrogen bonds do play an important role in the extent of crystalline enthalpy, using Hosemann's relation $\alpha^{*}=\mathrm{g} \mathrm{x}<\mathrm{N}>^{1 / 2}$, which is an empirical parameter introduced by Hosemann. It essentially means that the growth of paracrystalline disorder is controlled by the net plane structure. Normally, for polymers the value of enthalpy lies between 0.1 and 0.2 . 
Table 2

Hydrogen bond distance and energy of the hydrogen bonds for the natural fibers studied

\begin{tabular}{llccccccccc}
\hline \multirow{2}{*}{ Fibers } & \multicolumn{2}{c}{$3567 \mathrm{~cm}^{-1}$} & \multicolumn{2}{c}{$3423 \mathrm{~cm}^{-1}$} & \multicolumn{2}{c}{$3342 \mathrm{~cm}^{-1}$} & \multicolumn{2}{c}{$3278 \mathrm{~cm}^{-1}$} \\
\cline { 2 - 8 } & $\mathrm{E}_{\mathrm{H}}(\mathrm{kJ})$ & $\mathrm{R}(\AA)$ & $\mathrm{E}_{\mathrm{H}}(\mathrm{kJ})$ & $\mathrm{R}(\AA)$ & $\mathrm{E}_{\mathrm{H}}(\mathrm{kJ})$ & $\mathrm{R}(\AA)$ & $\mathrm{E}_{\mathrm{H}}(\mathrm{kJ})$ & $\mathrm{R}(\AA)$ & $\mathrm{E}$ \\
& 5.969 & 2.833 & 16.038 & 2.801 & 21.935 & 2.782 & 26.746 & 2.767 & 30.997 & 2.754 \\
Curaua & 5.980 & 2.833 & 16.038 & 2.801 & 21.827 & 2.783 & 26.538 & 2.768 & 30.666 & 2.755 \\
Jute & 5.667 & 2.833 & 16.253 & 2.800 & 22.043 & 2.782 & 27.041 & 2.766 & 30.781 & 2.755 \\
Kenaf & 6.048 & 2.832 & 16.325 & 2.800 & 22.100 & 2.782 & 26.782 & 2.767 & 31.140 & 2.754 \\
Ramie & 6.156 & 2.832 & 16.253 & 2.800 & 21.863 & 2.783 & 26.538 & 2.768 & 31.148 & 2.754 \\
Sisal & 6.185 & 2.832 & 16.253 & 2.800 & 22.366 & 2.781 & 27.041 & 2.766 \\
Buriti & & & & & & &
\end{tabular}

Table 3

Microstructural parameters for the vegetal fibers studied and their native cellulose

\begin{tabular}{lcccccccccc}
\hline Fibers & Reflection & $2 \theta\left(^{\circ}\right)$ & $<\mathrm{N}>$ & $\mathrm{P}$ & $\alpha$ & $\mathrm{g}(\%)$ & $\alpha^{*}$ & $\mathrm{~d}_{\text {hkl }}(\AA)$ & $\mathrm{D}_{\text {surf }}(\AA)$ & $\mathrm{D}_{\text {vol }}(\AA)$ \\
\hline \multirow{2}{*}{ Buriti } & $(100)$ & 15.55 & $5.99 \pm 0.02$ & 5.99 & 0.656 & $0.002 \pm 0.01$ & 7.26 & 5.690 & 38.42 & 38.42 \\
& $(200)$ & 22.00 & $8.09 \pm 0.05$ & 3.18 & 0.315 & $1.07 \pm 0.02$ & 6.80 & 4.035 & 36.58 & 39.98 \\
\multirow{2}{*}{ Curaua } & $(100)$ & 15.70 & $6.12 \pm 0.02$ & 4.79 & 0.349 & $0.002 \pm 0.02$ & 7.40 & 5.638 & 39.99 & 40.47 \\
& $(200)$ & 22.20 & $12.56 \pm 0.07$ & 12.43 & 0.255 & $2.57 \pm 0.02$ & 8.74 & 4.00 & 47.76 & 50.13 \\
\multirow{2}{*}{ Jute } & $(100)$ & 15.30 & $1.78 \pm 0.01$ & 0.08 & 0.477 & $0.92 \pm 0.02$ & 10.44 & 5.784 & 32.73 & 33.98 \\
& $(200)$ & 22.00 & $9.14 \pm 0.06$ & 5.13 & 0.269 & $2.12 \pm 0.03$ & 15.12 & 4.035 & 54.68 & 59.20 \\
\multirow{2}{*}{ Kenaf } & $(100)$ & 15.25 & $3.86 \pm 0.02$ & 2.52 & 0.622 & $1.47 \pm 0.02$ & 9.82 & 5.803 & 30.46 & 33.85 \\
\multirow{2}{*}{ Ramie } & $(200)$ & 22.00 & $8.06 \pm 0.04$ & 5.27 & 0.291 & $2.57 \pm 0.03$ & 14.20 & 4.035 & 41.64 & 43.98 \\
& $(100)$ & 15.25 & $4.88 \pm 0.02$ & 3.73 & 0.764 & $3.73 \pm 0.02$ & 11.05 & 5.803 & 35.99 & 39.04 \\
\multirow{2}{*}{ Sisal } & $(200)$ & 22.10 & $6.81 \pm 0.03$ & 3.71 & 0.301 & $1.83 \pm 0.02$ & 13.05 & 4.017 & 39.39 & 42.67 \\
& $(100)$ & 15.80 & $7.42 \pm 0.05$ & 5.97 & 0.259 & $0.005 \pm 0.03$ & 13.62 & 5.602 & 46.48 & 47.95 \\
\hline
\end{tabular}


RANJITHA KEMPAIAH et al.
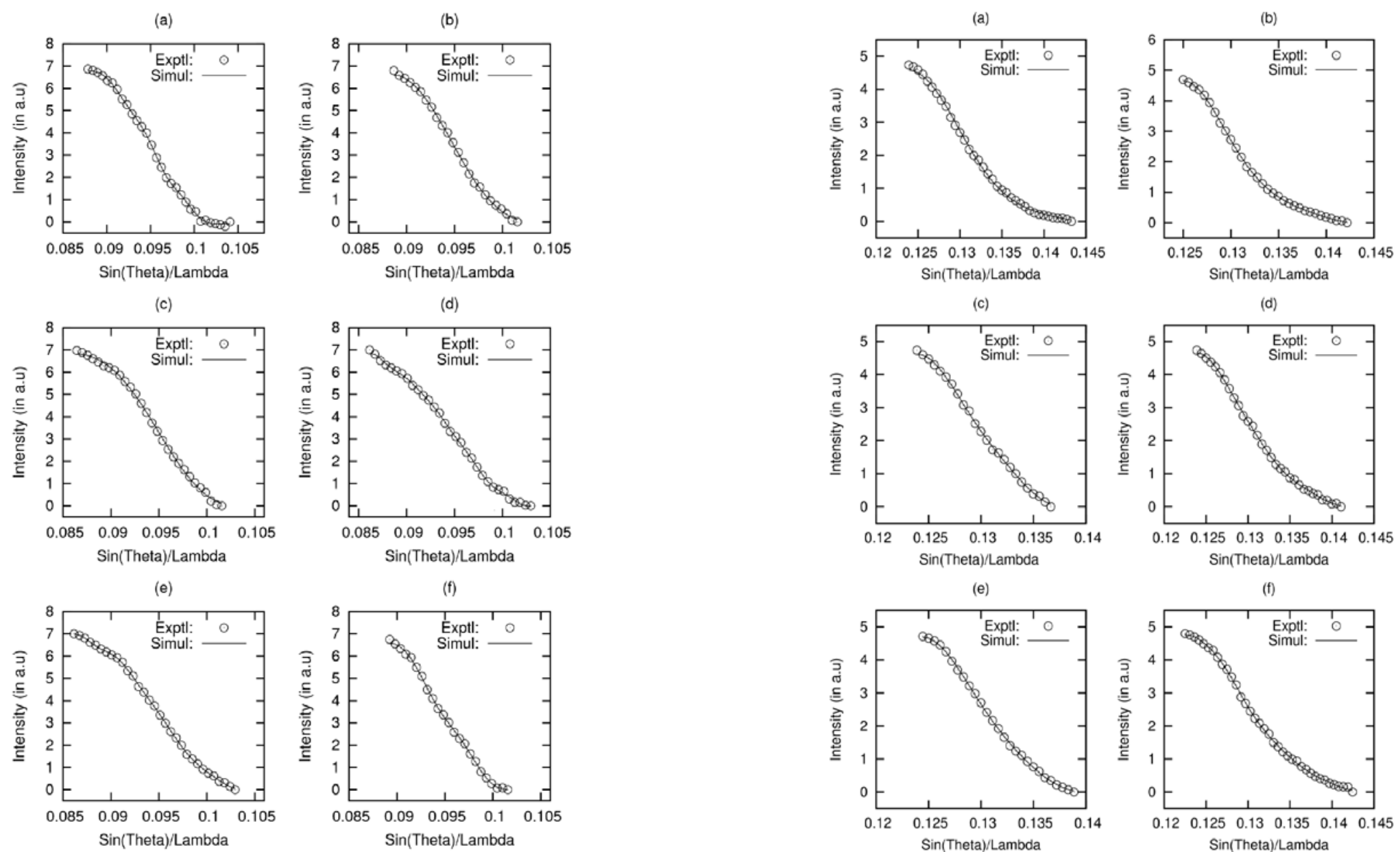

Figure 3: Experimental and simulated (110) reflection profile of a) buriti, b) curaua, c) jute, d) kenaf, e) ramie and f) sisal vegetal fibers
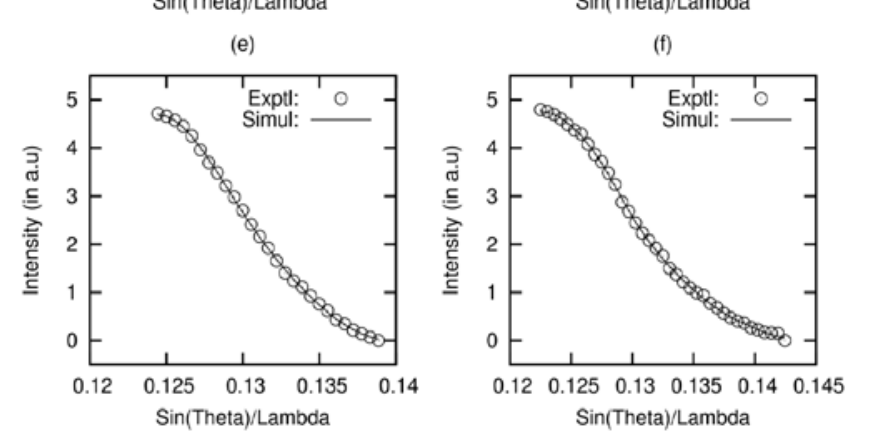

Figure 4: Experimental and simulated (200) reflection profile of a) buriti, b) curaua, c) jute, d) kenaf, e) ramie and f) sisal vegetal fibers 
(a)

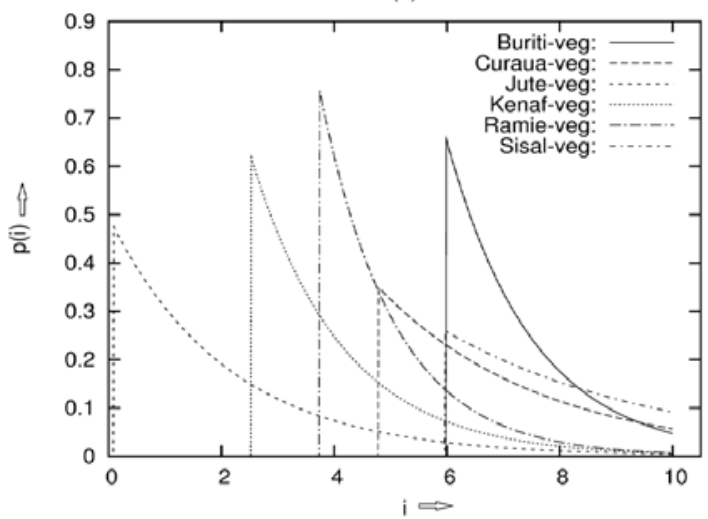

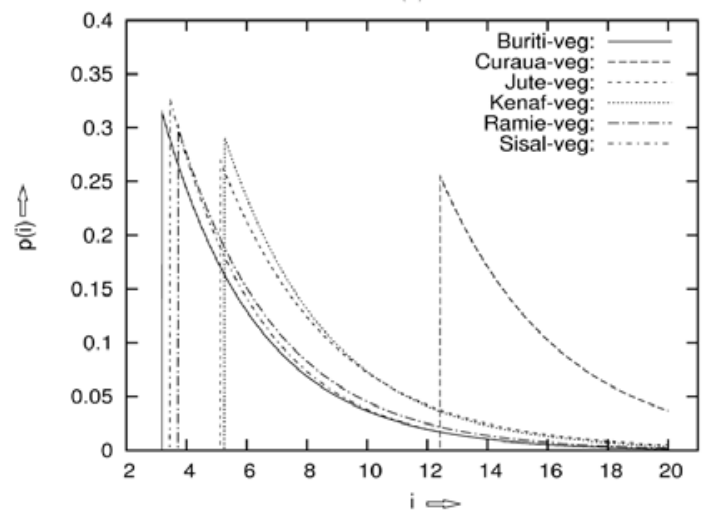

Figure 5: Variation of crystal size distribution along a) (110) and b) (200) reflection for buriti, curaua, jute, kenaf, ramie and sisal vegetal fibers

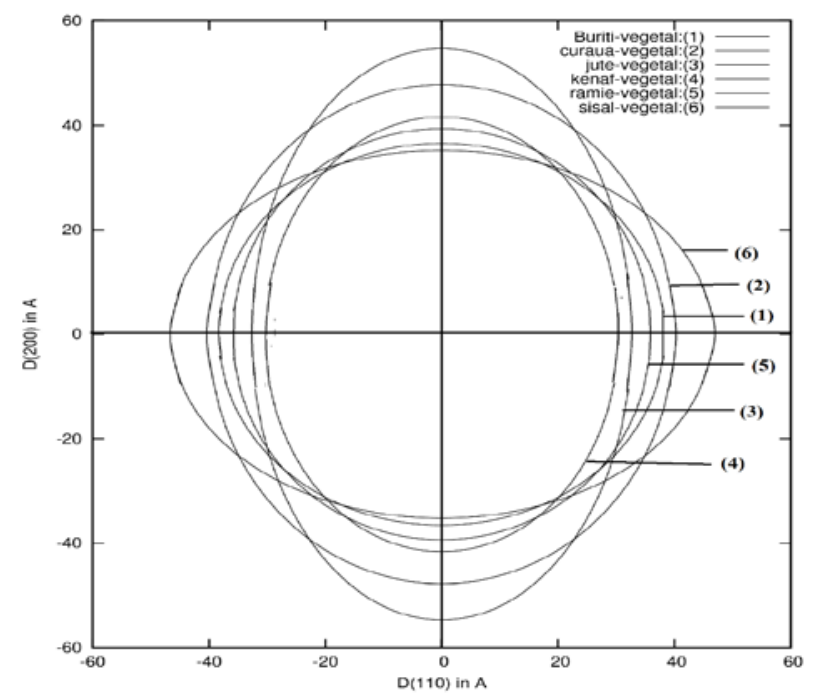

Figure 6: Variation of crystallite ellipsoid shape for (1) buriti, (2) curaua, (3) jute, (4) kenaf, (5) ramie and (6) sisal vegetal fibers

In the vegetal fibers and their native cellulose in this work, we find the value being less than 0.2. This may be explained by the fact that the strains present in the vegetal fibers and their native cellulose are very small, compared to other natural fibers, such as silk, and also man-made polymers. ${ }^{58,59}$ The crystallite shape is different in the studied varieties of vegetal fibers and their native cellulose, compared to other fibers. ${ }^{60}$

There is a variation of crystallite shape and size for vegetal fibers and their native cellulose caused by variation in the chemical composition of cellulose and lignin, present among fibers. ${ }^{36}$ Thus, the vegetal fibers and their native cellulose investigated in this work have larger values of crystallite shape and size. This finding is in agreement with an earlier report on man-made fibers. ${ }^{61}$

\section{CONCLUSION}

We have carried out FT-IR spectroscopy and $\mathrm{X}$-ray diffraction analyses on a variety of vegetal fibers and their native cellulose. It is observed that, even though there is not much change in the position of the X-ray reflections, a significant difference in microstructural parameters occurs for the vegetal fibers and their native cellulose. The changes in crystal imperfection parameters are quantified here in terms of microstructural parameters and chemical composition of cellulose and lignin. Also, as revealed by FT-IR spectroscopy, a strong broad band can be observed in the region of $3700-3000 \mathrm{~cm}^{-1}$, which is assigned to different $-\mathrm{OH}$ stretching modes. ${ }^{19}$ The intermolecular hydrogen bond in the phenolic group of lignin was recorded around 3568-3577 $\mathrm{cm}^{-1} \cdot{ }^{19}$ In cellulose, the hydrogen bond vibration 
appears around $3432 \mathrm{~cm}^{-1}$, 36,48 while another intermolecular hydrogen bond in cellulose normally occurs at $3342 \mathrm{~cm}^{-1}{ }^{48}$ These two significant characteristic bands assigned to the two crystalline cellulose allomorphs, cellulose $I_{\alpha}$ and cellulose $\mathrm{I}_{\beta}$, also occur in the region of 3220$3280 \mathrm{~cm}^{-1} \cdot 41,42$ Our study indicated that the investigated vegetal fibers and their native cellulose have larger values of crystallite shape and size. Surprisingly, we observed that the strains present in the vegetal fibers and their native cellulose are very small. Thus, by the methods used here, our study provides deeper understanding of the structure and properties of vegetable fibers, which is necessary before exploring their potential as reinforcing fillers in composite formulations.

ACKNOWLEDGEMENT: Authors (V.A., R.K. and GG) thank the Chairman, Vice-Chairman and Principal of the Sambhram Institute of Technology, Banglore, for providing research facilities. M.P. thanks National Council for Scientific and Technological Development (CNPq/Brazil), grant number 435110/2018-7. R.S. thanks UPE and CPEPA major research project Vignana bhavan, University of Mysore, Mysore.

\section{REFERENCES}

1 Y. Chen, M. A. Tshabalala, J. Gao, N. M. Stark, Y. Fan et al., Thermochim. Acta, 591, 40 (2014), https://doi.org/10.1016/j.tca.2014.06.012

2 S. Sheshmani, Carbohyd. Polym., 94, 416 (2013), https://doi.org/10.1016/j.carbpol.2013.01.067

3 C. Tenorio and R. Moya, Thermochim. Acta, 563, 12 (2013), https://doi.org/10.1016/j.tca.2013.04.005

4 G. Han, S. Huan, J. Han, Z. Zhang and Q. Wu, Materials, $\quad 7, \quad 16 \quad$ (2014), https://doi.org/10.3390/ma7010016

5 M. Poletto, A. J. Zattera and R. M. C. Santana, J. Appl. Polym. Sci., 126, E337 (2012), https://doi.org/10.1002/app.36991

6 H. L. Ornaghi Jr., M. P. Poletto, A. J. Zattera and S. C. Amico, Cellulose, 21, 177 (2014), https://doi.org/10.1007/s10570-013-0094-1

D. Romanzini, H. L. Ornaghi Jr., S. C. Amico and A. J. Zattera, J. Reinf. Plast. Compos., 31, 1652 (2012), https://doi.org/10.1177/0731684412459982

8 D. Klemm, B. Heublein, H. P. Fink and A. Bohn, Angew. Chem. Int. Ed., 44, 3358 (2005), https://doi.org/10.1002/anie.200460587

9 M. Åkerholm, B. Hinterstoisser and L. Salmén, Carbohyd. Res., 339, $569 \quad$ (2004), https://doi.org/10.1016/j.carres.2003.11.012
10 S. Y. Oh, D. I. Yoo, Y. Shin, H. C. Kim, H. Y. Kim et al., Carbohyd. Res., 340, 2376 (2005), https://doi.org/10.1016/j.carres.2005.08.007

11 S. Nam, A. D. French, B. D. Condon and M. Concha, Carbohyd. Polym., 135, 1 (2016), https://doi.org/10.1016/j.carbpol.2015.08.035

12 R. J. Moon, A. Martin, J. Nairn, J. Simonsen and J. Youngblood, Chem. Soc. Rev., 40, 3941 (2011), https://doi.org/10.1039/C0CS00108B

13 P. Zugenmaier, Pure Appl. Chem., 78, 1843 (2006), https://doi.org/10.1351/pac200678101843

14 H. Hoogsteen, A. R. Postema, A. J. Pennings, G. T. Brinke and P. Zugenmaier, Macromolecules, 23, 634 (1990), https://doi.org/10.1021/ma00204a041

15 M. J. John and S. Thomas, Carbohyd. Polym., 71, 343

(2008),

https://doi.org/10.1016/j.carbpol.2007.05.040

16 A. Gandini, Green Chem., 13, 1061 (2011), https://doi.org/10.1039/C0GC00789G

17 A. O’Sullivan, Cellulose, 4, 173 (1997), https://doi.org/10.1023/A:1018431705579

18 E. I. Hult, T. Iversen and J. Sugiyama, Cellulose, 10, 103

(2003), https://doi.org/10.1023/A:1024080700873

19 M. Poletto, V. Pistor and A. J. Zattera, in "Cellulose - Fundamental Aspects", edited by Theo van de Ven and Louis Godbout, IntechOpen, 2014, pp. 45-68, https://doi.org/10.5772/50452

20 Y. Takahashi and H. Matsunaga, Macromolecules, 24, 3968 (1991), https://doi.org/10.1021/ma00013a035 21 U. J. Kim, S. H. Eom and M. Wada, Polym. Degrad. Stabil., 95, $778 \quad$ (2010), https://doi.org/10.1016/j.polymdegradstab.2010.02.009 22 Y. Habibi, L. A. Lucia and O. J. Rojas, Chem. Rev., 110, 3479 (2010), https://doi.org/10.1021/cr900339w

23 H. L. Ornaghi Jr., A. S. Bolner, R. Fiorio, A. J. Zattera and S. C. Amico, J. Appl. Polym. Sci., 118, 887 (2010), https://doi.org/10.1002/app.32388

24 B. E. Warren and B. L. Averbach, J. Appl. Phys., 21, 595 (1950), https://doi.org/10.1063/1.1699713

25 B. E. Warren, Acta Cryst., 8, 483 (1955), https://doi.org/10.1107/S0365110X55001503

26 B. E. Warren, “X-Ray Diffraction”, New York, Addison-Wesley, 1969.

27 H. P. Fink, D. Hofmann and B. Philipp, Cellulose, 2, 51 (1995), https://doi.org/10.1007/BF00812772

28 J. Haase and B. Renwanz, Kolloid-Z. Z. Polym., 250, 503 (1972), https://doi.org/10.1007/BF01521246

29 J. Haase, R. Hosemann and B. Renwanz, Kolloid-Z. Z. Polym., 251, 871 (1973), https://doi.org/10.1007/BF01520918

30 J. Haase, R. Hosemann and B. Renwanz, Cellulose Chem. Technol., 9, 513 (1975), http://www.cellulosechemtechnol.ro/

31 D. Hofmann and E. Walenta, Polymer, 28, 1271 (1987), https://doi.org/10.1016/0032-3861(87)90436-8 
32 D. Hofmann, H. P. Fink and B. Philipp, Polymer, 30, 237 (1989), https://doi.org/10.1016/00323861(89)90111-0

33 I. H. Hall and R. Somashekar, J. Appl. Cryst., 24, 1051

https://doi.org/10.1107/S0021889891007707

(1991),

34 R. Somashekar and H. Somashekarappa, J. Appl. Cryst., $\quad 30, \quad 147 \quad$ (1997), https://doi.org/10.1107/S0021889896010023

35 R. Somashekar, H. Somashekarappa, G. Subramanyam and U. D. Prahllad, Eur. Polym. J., 33, $963 \quad$ (1997), https://doi.org/10.1016/S00143057(96)00149-8

${ }^{36}$ M. Poletto, H. L. Ornaghi Jr. and A. J. Zattera, Materials, 7, $6105 \quad$ (2014), https://doi.org/10.3390/ma7096105

37 A. D. French and M. S. Cintrón, Cellulose, 20, 583 (2013), http://dx.doi.org/10.1007/s10570-012-9833-y

38 R. A Young, R. J. Gerdes and A. J. C. Wilson, Acta Cryst., 22, 155 (1967), https://doi.org/10.1107/S0365110X67000271

39 R. Somashekar, I. H. Hall and P. D. Carr, J. Appl. Cryst., 22, 363 (1989), https://doi.org/10.1107/S0021889889004085

40 I. H. Hall and R. Somashekar, J. Appl. Cryst., 24, 1051

(1989),

https://doi.org/10.1107/S0021889891007707

${ }^{41}$ H. Yang, R. Yan, H. Chen, D. H. Lee and C. Zheng, Fuel, 86, 1781 (2007), https://doi.org/10.1016/j.fuel.2006.12.013

42 C. M. Popescu, G. Singurel, M. C. Popescu, C. Vasile, D. S. Argyropoulos et al., Carbohyd. Polym., 77, 851

(2009),

https://doi.org/10.1016/j.carbpol.2009.03.011

${ }^{43}$ H. Yokoi, T. Nakase, K. Goto, Y. Ishida, H. Ohtani et al., J. Anal. Appl. Pyrol., 67, 191 (2003), https://doi.org/10.1016/S0165-2370(02)00061-X

${ }_{4}$ Y. Ishida, K. Goto, H. Yokoi, S. Tsuge, H. Ohtani et al., J. Anal. Appl. Pyrol., 78, 200 (2007), https://doi.org/10.1016/j.jaap.2006.06.009

45 E. Mészáros, E. Jakab and G. Várhegyi, J. Anal. Appl. Pyrol., 79, $61 \quad$ (2007), https://doi.org/10.1016/j.jaap.2006.12.007

46 M. C. Popescu, C. M. Popescu, G. Lisa and Y. Sakata, J. Mol. Struct., 988, 65 (2011), https://doi.org/10.1016/j.molstruc.2010.12.004

47 I. Carrilo, R. T. Mendonça, M. Ago and O. J. Rojas, Cellulose, 25, $1011 \quad$ (2018). https://doi.org/10.1007\%2Fs10570-018-1653-2

${ }^{48}$ T. Kondo, Cellulose, 4, 281 (1997), https://doi.org/10.1023/A:1018448109214

49 C. M. Popescu, M. C. Popescu and C. Vasile, Carbohyd. Polym., 79, $362 \quad$ (2010), https://doi.org/10.1016/j.carbpol.2009.08.015

50 H. Struszczyk, J. Macromol. Sci., 23, 973 (1986), https://doi.org/10.1080/00222338608081105
51 G. C. Pimentel and C. H. Sederholm, J. Chem. Phys., $\quad 24, \quad 639$ (1956), https://doi.org/10.1063/1.1742588

52 C. M. Popescu, M. C. Popescu, G. Singurel, C. Vasile, D. S. Argyropoulos et al., Appl. Spectrosc., 61 1168 (2007), https://doi.org/10.1366/000370207782597076

53 M. Poletto, M. Zeni and A. J. Zattera, J. Thermoplast. Compos. Mater., 25, 821 (2012), https://doi.org/10.1177/0892705711413627

54 W. Press, B. P. Flannery, S. Teuklosky and W. T. Vettering, "Numerical Recipes", New York, Cambridge University Press, 1988, p. 284

55 S. Abhishek, O. M. Samir, V. Annadurai, R. Gopalkrishne Urs, S. S. Mahesh et al., Eur. Polym. J., 41, 2916

(2005),

https://doi.org/10.1016/j.eurpolymj.2005.06.005

56 Sangappa, B. Lakshmeesha Rao, S. Asha, R. Madhu Kumar et al., Compos. Interfaces, 21, 153 (2014), https://doi.org/10.1080/15685543.2013.855485

57 H. Somashekarappa, V. Annadurai, Sangappa, G. Subramanya and R. Somashekar, Materials Letters, 53, 415 (2002), https://doi.org/10.1016/S0167577X(01)00517-1

58 R. Hosemann, Colloid. Polym. Sci., 260, 864 (1982), https://doi.org/10.1007/BF01419097

59 V. Annadurai, G. Subramanyam, R. Goplakrishne Urs and R. Somashekar, J. Appl. Polym. Sci., 79, 1979 (2001), $\quad$ https://doi.org/10.1002/10974628(20010314)79:11<1979::AID-

APP1005>3.0.CO;2-Y

60 K. Ranjitha, G. Gayathri, R. Tomar, M. Poletto, V. Annadurai et al., AIP Conf. Procs., 1859, 020054 (2017), https://doi.org/10.1063/1.4990207

61 K. G. Lee, R. Barton Jr. and J. M. Schultz, J. Polym. Sci. (Part B), 33, 1 (1995), https://doi.org/10.1002/polb.1995.090330101

62 O. Faruk, A. K. Bledzki, H. Fink and M. Sain, Prog. Polym. Sci., 37, 1552 (2012), https://doi.org/10.1016/j.progpolymsci.2012.04.003

63 A. K. Bledzki and J. Gassan, Prog. Polym. Sci., 24, $221 \quad$ (1999), https://doi.org/10.1016/S00796700(98)00018-5

64 N. C. Cordeiro, A. G. O. Gouveia, A. M. Moraes and S. C. Amico, Carbohyd. Polym., 84, 110 (2011), https://doi.org/10.1016/j.carbpol.2010.11.008

65 K. G. Satyanarayana, J. L. Guimarães and F. Wypych, Compos. Part A, 38, 1694 (2007), https://doi.org/10.1016/j.compositesa.2007.02.006 66 H. L. Ornaghi Júnior, A. G. O. Moraes, M. Poletto, A. J. Zattera and S. C. Amico, Cellulose Chem. Technol., $\quad 50, \quad 15 \quad$ (2016), http://www.cellulosechemtechnol.ro/pdf/CCT1(2016)/ p.15-22.pdf 